\title{
Un acercamiento multidisciplinario al rol orientador del docente en el contexto comunitario y educativo
}

\author{
Jesús Morales \\ Doctor en Antropología \\ Docente e investigador \\ Universidad de los Andes, Venezuela \\ lectoescrituraula@gmail.com \\ ORCID: https://orcid.org/0000-0001-8533-3442
}

Recepción: 21-10-2019 / Aceptación: 26-12-2019

\section{Resumen}

El escenario educativo, por ser el lugar de confluencia de diversas prácticas sociales y culturales, se ha convertido en un espacio convulsionado y saturado de controversias; así como de situaciones problemáticas que ameritan el uso de estrategias de intervención grupal e individualizadas como: la promoción de habilidades sociales, el trabajo en equipo, el manejo de competencias emocionales y la resolución pacífica de conflictos. Todas estas estrategias propician las condiciones oportunas para que el estudiante y los demás actores educativos logren resolver -bien sea por sí mismo o con la cooperación de terceroslos conflictos personales, emocionales, afectivos, educativos y sociales que imposibilitan la consolidación de formas de vida óptimas y saludables.

En atención a lo expuesto, el contenido del artículo diserta sobre el rol orientador del docente en el contexto comunitario y educativo, desde una perspectiva multidisciplinaria que permita integrar los aspectos, aportaciones y acciones concretas que su quehacer le ofrece al desarrollo humano integral y a la transformación de los escenarios educativo y comunitario.

Palabras clave: Orientación comunitaria, participación social, cohesión grupal, habilidades, competencias.

\begin{abstract}
The educational setting, for being the place of confluence of various social and cultural practices, has become a convulsed space and saturated with controversies; as well as problematic situations that merit the use of individual and group intervention strategies such as the promotion of social skills, teamwork, management of emotional competences, and peaceful solution of conflicts. All these strategies provide the appropriate conditions for the student and the other educational actors to solve - either by themselves or with the cooperation of third parties - personal, emotional, affective, educational, and social conflicts that precludes the consolidation of optimal and healthy ways of life.

In attention to the expressed above, the content of the article discourse about the guiding role of the professor in the community and educational context, from a multidisciplinary perspective that allows integrating the aspects, contributions, and concrete actions that their work offers to integral human development and transformation of the educational and community settings.
\end{abstract}

Keywords: Community orientation, social participation, group cohesion, skills, competences. 


\section{Introducción}

Los cometidos de la educación en el presente siglo han enfocado sus esfuerzos en garantizar la atención de las diversas dimensiones del ser humano, por comprender que el verdadero desarrollo se logra mediante la creación de condiciones óptimas de libertad individual, formulación de políticas inclusivas y de oportunidades para recibir la formación integral. Esto coadyuve en el proceso de constituirse en un agente activo, capaz de asumir con compromiso social los problemas que atentan contra su bienestar; entre los cuales, según Sen (2000), se identifican "la pobreza, la privación en el acceso a los medios de atención social y la restricción de las libertades para participar en la vida social, política y económica de la comunidad" (p.20).

En respuesta a este cúmulo de aspectos, la educación para la ciudadanía mundial ha planteado, entre otras cosas, la construcción de escenarios y condiciones en los que el sujeto logre la integración a los planes formativos, goce de las bondades de la educación inclusiva y de calidad; se coopere con la erradicación del analfabetismo y el fracaso escolar, así como búsqueda de mayores oportunidades que permitan reducir la brecha de desigualdad que, históricamente, ha procurado imponerse en unos contextos más que en otros. Estos propósitos, ampliamente expuestos en los programas de educación para la ciudadanía, más allá de propiciar el desarrollo intelectual se han fundamentado en la atención de las necesidades individuales y la promoción de nuevos modos de alfabetización, que hagan posible el respeto a la diversidad y el pluralismo, así como el uso del diálogo y las habilidades sociales, como condiciones de las que depende el bienestar integral y la convivencia humana (UNESCO, 2015).

Es así que, orientar se posiciona y debe entenderse dadas las exigencias de la sociedad del siglo XXI, como un proceso relacionado con el desarrollo pleno de la personalidad y de las competencias necesarias para la realización personal. Para Lipovetsky (2000) pudiera interpretarse como la disposición autónoma y responsable para asumir, desde los principios ciudadanos, el reconocimiento de su rol social, la identificación de sus capacidades humanas y la sensibilidad para construir redes de colaboración, que permitan la participación democrática, el consenso, el reconocimiento del otro y su integración; aspectos que se entienden como el sustento de la calidad de vida.

En un contraste entre los cometidos mencionados y los propósitos de la orientación educativa, es posible deducir que, la educación para la vida (Torres, 1999) emerge como un planteamiento alternativo. Esto, junto a teoría de las capacidades (Sen, 2000), procuran maximizar las condiciones inherentes al desarrollo humano; al integrar como opciones vitales para el entendimiento y la tolerancia, para enfrentar oportunamente los cambios permanentes y asumir con ética las cuestiones sociales. Ante esto solo es posible actuar con flexibilidad, creatividad y con disposi- 
ción suficiente para adaptarse al dinamismo propio de las relaciones humanas. Por ello se diserta el rol orientador del docente en el contexto comunitario y educativo, desde una perspectiva multidisciplinaria que permita integrar los aspectos, aportaciones y acciones concretas que su quehacer le ofrece al desarrollo humano.

\section{Desarrollo}

\section{El rol orientador del docente en la actualidad}

El compromiso social de la educación y las iniciativas para consolidar acciones efectivas de desarrollo humano constituyen en la actualidad aspectos que transversalizan los programas que, a nivel mundial, procuran la búsqueda de condiciones de vida más justas y equitativas. Ello implica, entre otras cosas, lograr que el individuo consolide competencias relacionadas con la defensa de sus libertades fundamentales, el fomento de la solidaridad y la disposición de sus capacidades para influir en el mundo y formular procesos de ayuda en terceros (UNESCO, 2015); permitiendo de este modo formas de vida plenas y prolongadas en el tiempo (Sen, 2000).

Por ende, la responsabilidad con la formación de generaciones comprometidas con su propio desarrollo humano se entiende como la premisa que permea todos los niveles educativos. Esto, en parte, se debe a la emergencia cada vez más pronunciada de factores que perturban la consolidación de habilidades y competencias, que le permitan al individuo responder a las necesidades sociales propias del contexto en el que hace vida. Para comprender las situaciones que experimenta la humanidad, Goleman (1998) expone que "la actual generación de niños padece más problemas emocionales y, hablando en términos generales, suelen ser más solitarios, deprimidos, irascibles, desobedientes, nerviosos, inquietos, impulsivos y agresivos que la generación precedente" (p.28).

Para Lipovetsky (2000), esta caracterización de la vida humana en la actualidad refiere a un estado de conmoción y emergencia, en el que "la aparición de nuevos modos de socialización e individuación han dado lugar a valores hedonistas y permisivos, a partir de los cuales han emergido dos situaciones: erosión de las identidades sociales y desestabilización acelerada de las personalidades" (p.5). Lo anterior permite explicar que, el siglo que atravesamos se encuentra trastocado funcionalmente por la aparición de conflictos tales como: discriminación, violencia, agresión, xenofobia, luchas de poder, irrespeto a la diversidad y dificultades para reconocer al otro, al que se asume diferente por razones sociales o culturales. Estas situaciones conflictivas indican que nos encontramos ante el reto de intervenir oportunamente para generar equilibrio y bienestar social (Morales, 2018b).

Ante este panorama, la función orientadora del docente en el contexto educativo y comunitario toma mayor pertinencia, pues sobre esta recaen responsabilidades importantes enfocadas en propiciar la atención a las diversas dimensiones del ser humano, mediante las 
cuales se busca satisfacer necesidades fundamentales vinculadas con "protección, afecto, entendimiento, creación, participación, ocio e identidad; es decir, posibilitar que logre por sí mismo la capacidad de ver, pensar, reconocer, moverse, tener planes" (Elizalde, 2012, p.10).

Según los principios de la educación para la ciudadanía mundial, los aspectos mencionados se complementan con los desafíos de la formación integral en el siglo XXI, los cuales apuntan a la necesidad de integrar acciones en las que se aborden dimensiones del vivir y convivir, entre las que destacan: educación de sus emociones, el incremento de la motivación y el logro de sus objetivos personales; fomentar la autoexploración, la autodisciplina y el desarrollo de competencias sociales que le permitan adoptar actitudes adecuadas con las demandas de su contexto (Sarramona, 2002). En palabras de Bisquerra (2009), orientar en momentos cruciales -como los que se experimentan- implica un elevado compromiso docente, que se vea reflejado en promover habilidades comunicativas, de integración grupal y de motivación para sobrellevar los conflictos que emergen recurrentemente del espacio de convivencia.

Goleman (1998), desde los postulados de inteligencia emocional, coincide al afirmar que la orientación constituye un proceso inherente al desarrollo humano que persigue, por los cambios recurrentes, la consolidación de capacidades como "comunicarse, adaptarse a los contratiempos, trabajar grupalmente y responder con eficiencia y liderazgo a los obs- táculos" (p.30). Este cúmulo de competencias refiere implícitamente a procesos de autogestión, de los que depende que el individuo logre potenciar su capacidad para integrarse socialmente; es decir, proceder responsablemente con empatía, conciencia social, reconocimiento del otro y respeto a la diversidad.

Montero (2004) propone que orientar en tiempos complejos requiere de un proceso sinérgico, en el que se integren esfuerzos sociales, familiares y comunitarios para atener de modo efectivo los desbalances, necesidades y conflictos que experimenta el sujeto en la actualidad. Desde la psicología social, esto significa trabajar con el individualismo y fomentar el compromiso personal y colectivo con el crecimiento propio, y de quienes son parte del contexto en el que el sujeto hace vida. En otras palabras, la orientación como proceso socioeducativo procura el reconocimiento y la integración del individuo a las reglas morales, a la búsqueda del sentido de continuidad y responsabilidad; condiciones que por sus implicaciones dan lugar a la definición de proyectos de vida, de metas y objetivos de los que depende la consolidación de acciones presentes y futuras.

En este sentido, el rol orientador del docente se entiende como el resultado de la unificación de esfuerzos provenientes de la familia, la escuela y la sociedad en general, como pilares sobre los que recaen funciones importantes para el desarrollo humano integral. Entre estas precisan: potenciar las virtudes humanas, educar con pertinencia social $y$ 
promover el logro de los ideales necesarios, que permiten la transformación del mundo y convertirse en mejores personas, que cooperen con la construcción de una sociedad justa y equitativa como premisas que guíen el comportamiento social.

Al respecto, los aportes de la psicología humanista definen que la orientación como proceso educativo debe proveer las condiciones para que afloren capacidades, habilidades y competencias, que le permitan al ser humano no solo descubrir su posición en el mundo, sino asumir la dirección de su futuro (Maslow, 1954; Rogers, 1989). En atención a lo anterior, el psicoanálisis ha propuesto como premisas fundamentales para lograr este nivel de madurez en el sujeto, el manejo de la estabilidad mental y emocional como procesos que coadyuvan a minimizar los efectos de los conflictos sociales, y la tendencia destructora a las que por sus repercusiones deben ser resueltas, con el afán de optimizar "la adaptación del individuo al tipo de vida de su sociedad" (Fromm, 1964, p.18).

En tanto, la educación emocional ha propuesto la necesidad de aprender a gestionar sus propias experiencias y el manejo de sus procesos psíquicos básicos, de los que depende el funcionamiento mental y social necesario para resolver de manera satisfactoria las situaciones que emergen de la relación del sujeto con sus semejantes. Por ello, se entiende que la orientación es un proceso integral que coadyuva con la resolución de conflictos; y el desarrollo de mayores niveles de sensibilidad ante las si- tuaciones que otros experimentan. Todo eso requiere del sentido de cooperación y de fraternidad como valores que medien las relaciones de ayuda hacia otros. Para Fromm (1964), orientar no es más que guiar al ser humano para que descubra cómo responder y enfrentar las situaciones sociales, las cuales exigen el cumplimiento de "exigencias básicas que garanticen su desenvolvimiento humano" (p.24).

En síntesis, la labor orientadora del docente como actor socioeducativo, no es más que la unificación de funciones importantes que van más allá de la socialización y la adaptación del individuo a la vida colectiva. Su rol como agente de cambio y transformación trasciende los procesos de acompañamiento, orientación y guiatura hacia la atención integral colectiva e individualizada, como acciones de las que depende la consolidación de competencias socio-emocionales, afectivas y personales; las que se entienden como condiciones necesarias para configurar una personalidad consistente, capaz de interactuar sensible, comprometida y empáticamente con su contexto. Esto indica que, orientar en la actualidad cumple propósitos relevantes como: la búsqueda del bien común, el sentido de pertenencia, la integración altruista a la convivencia social y la configuración de una personalidad pro-social.

\section{La orientación en el contexto educativo y comunitario}

Las metas de la orientación educativa, así como su radio de acción, se han ampliado durante los últimos años, extendiéndose a la atención 
de necesidades vinculadas con la educación intercultural, la cohesión social y el manejo de las tensiones en las que se encuentra inmersa tanto la escuela como el escenario comunitario. Al respecto, Sarramona (2002) propone la vida en sociedad pese a la existencia de políticas educativas efectivas; exige la promoción de valores globales como "aprender a vivir juntos, aprender a sobrellevar las diferencias culturales; aprender a participar en la vida colectiva y aprender a desarrollar las potencialidades del ser, como aspectos fundamentales para erradicar la discriminación y posibilitar la igualdad de oportunidades" (p.66).

Por tal motivo, intervenir y generar transformaciones en el escenario educativo constituyen cometidos con implicaciones trascendentales en el contexto comunitario, que van desde formación general que integre -sinérgicamente- a la familia y escuela en el cumplimiento de objetivos comunes, relacionados con la dinámica escolar y el afrontamiento de los conflictos socioeducativos. A este encuentro entre estos factores de socialización, la orientación educativa le ha brindado estrategias efectivas como "la resolución de nuevas situaciones con claridad de meta, diálogo y flexibilidad, en un diálogo escuela-familia como medio para buscar puntos de encuentro y evitar posibles conflictos" (Sarramona, 2002, p.67).

Lo dicho implica, entre otras cosas, que el rol de la orientación como parte del proceso educativo involucra no solo el tratamiento de las relaciones que se dan a nivel institucional, sino el abordaje de situaciones vinculadas con la integración del individuo a sus funciones sociales y a las condiciones reales, como requerimientos que exigen acompañarlo para que descubra el sentido de la responsabilidad del que dependen: el desarrollo de vínculos de empatía, de interacción y vinculación afectiva; así como la configuración de una personalidad cooperativa que defina su disposición para la vida social.

Montero (2004) manifiesta que orientar, además de generar procesos de atención individual y grupal, procura la creación de condiciones para que el sujeto despliegue competencias sociales y personales, que le permitan niveles significativos de bienestar en sus diversas dimensiones: satisfacción de necesidades de realización, estimulación intelectual, bienestar (espiritual, emocional, mental) y el crecimiento cognoscitivo del que depende la racionalización de su funcionamiento social. Se trata de hacer compatible y estrechar vínculos entre la educación intercultural con la socialización general como fundamentos, sobre los cuales cimentar la convivencia y el desarrollo integral del individuo.

En este sentido, orientar se entiende como una actividad propia del docente que persigue. entre otros aspectos, que el ser humano en formación logre regular su dimensión emocional, afectiva y sentimental; ejercitar su autocontrol frente a la crítica, la discriminación y la violencia, con el propósito de minimizar las actitudes y respuestas hostiles que dificultan el normal funcionamiento del 
escenario socioeducativo. Se trata, entonces, de involucrar al estudiante en experiencias personales en las que logre accionar sus capacidades para negociar disputas y llegar a consensos, a través de procesos comunicativos que le posibiliten explorar formas alternativas de resolver conflictos, en los que se eviten riesgos derivados de la agresión y el maltrato.

Para lograr estos cometidos Corkille (1970) plantea que la necesidad de fortalecer la imagen propia y el autoconcepto, a través del uso de la conciencia interna que le posibiliten al sujeto "superar los obstáculos, entendiéndolos como retos que requieren coherencia interna y el despliegue de competencias mentales que garanticen respuestas apropiadas ante los cambios y ante lo nuevo; lo que implica aventurarse en lo desconocido con seguridad y confianza" (p.44).

Para Bisquerra y Pérez (2007), tales cometidos requieren de la promoción y el desarrollo de "competencias para afrontar la vida diaria de forma sana y equilibrada a través de la regulación de las emociones y los sentimientos" (p.11). Esto de algún modo refiere a la orientación como el proceso que hace posible el fortalecimiento y la atención de todas las dimensiones del ser humano, entre las que se pueden mencionar: el compromiso personal y colectivo; la libertad de pensamiento y el rompimiento de los mecanismos impositivos y alienantes, que han subordinado la condición humana y "las oportunidades para el crecimiento intelectual, afectivo, humano y social, así como la posibilidad de participar en la construcción de mayores niveles igualdad y bienestar integral" (Daros, 2009, p.11).

Por su parte, Illich (1985), como crítico de la modernidad, asume a este movimiento como un elemento medular dentro de los procesos educativos, al configurar nuevas relaciones con implicaciones que se enmarcan en el fortalecimiento de los nexos de interdependencia; condición que, por no darse efectivamente, ha generado formas de pobreza en todas las dimensiones de lo humano, que se expresan en "la pérdida de poder sobre las circunstancias en conjugación con una pérdida del potencial personal" (p.5). Ante tales circunstancias, la labor del orientador debe enfocarse en acompañar a los más desfavorecidos en el compromiso de superar sus desventajas, a través de planes especiales que coadyuven con incremento de los niveles de competitividad frente a las demandas sociales.

Desde esta perspectiva, a la orientación como parte del proceso educativo, se asume como la guiatura que debe recibir el estudiante y que involucra actividades asociadas con la atención de situaciones conflictivas, y con el perfeccionamiento de las habilidades sociales y personales, de las que depende el fortalecimiento de relaciones interpersonales y la integración efectiva del orientado en la vida cotidiana. Todas ellas tienen como propósito garantizar, según exponen Ponce y otros (2018), su "desarrollo cognitivo, social, cultural y existencial a través de labores de acompañamiento cercano, sistemático y permanente" (p.218). 
Se trata de formar sujetos capaces de hacer frente de manera activa, y con la disposición necesaria para resolver problemas y asumir retos, acudiendo a la valoración equilibrada y correcta de sus potencialidades; recursos y habilidades desde las cuales emitir respuestas idóneas, que aplicadas a cualquier realidad, den como resultado la generación de cambios significativos y trascendentales no solo para el beneficio propio, sino en el crecimiento de otros que hacen parte importante de su contexto. De allí que, la psicología humanista haya enfocado sus esfuerzos en fomentar relaciones interpersonales sólidas, nexos de cooperación, de empatía y altruismo como estrategias para minimizar el individualismo y despertar el interés por los intereses colectivos.

Por su parte, Colls y otros (1998) dejan entrever que las funciones de la orientación como complemento de la actividad educativa en el siglo XXI; enfocan sus propósitos en hacer posible "la atención a la diversidad desde un compromiso ético en el que brinden las condiciones y el clima favorable para el aprendizaje, la innovación, el establecimiento de relaciones cooperativas y de liderazgo como requerimientos para construir mayores niveles de co-responsabilidad y autonomía" (p.7). Esta postura afirma que la creación de un ambiente idóneo representa -desde el clima organizacional y educativo- un requerimiento del que depende la potenciación del autodesarrollo y de la creatividad, tanto de los docentes como de los estudiantes y, en su defecto, del escenario social.
A los primeros, les ayuda a realizar adaptaciones curriculares pertinentes y justificadas a partir de las necesidades reales; mientras que a los estudiantes y a los actores sociales les despierta el interés y la motivación por aprender de manera significativa, como instrumento necesario para la obtención de resultados trascendentales y de soluciones efectivas que mejoren las condiciones colectivas de vida. En función de lo expuesto, y retomando los planteamientos de Colls y otros (1998), el orientador además de ofrecer relaciones de ayuda, cooperación y promover el desarrollo integral, también cuenta con atribuciones importantes que procuran atender al individuo desde "sus particularidades, características y valores, con el objetivo de lograr procesos educativos de calidad, capaces de adaptarse de manera amplia a las exigencias propias del curriculum, entre las que destacan: la atención a la diversidad y al potencial del orientado" (p.8).

Al respecto, Cañas, Campoy y Pantoja (2005) plantean que la asesoría en materia psicopedagógica se encuentra definida como el área estratégica que persigue la construcción conjunta de alternativas y técnicas que dinamicen los procesos de enseñanza y aprendizaje, así como la oferta de recomendaciones que definan el rumbo a seguir cuando se trata de "enfrentar los problemas educativos, atendiendo de manera personalizada y grupal y, ejerciendo acciones y tutorías que orienten teniendo como marco de acción la integración de los cometidos del curriculum escolar" (p.2). 
Esta postura es igualmente compartida por García y González (2010) quienes, haciendo referencia a la relación docente-estudiante, definen la orientación educativa como "una actividad cuyo propósito es acompañar, asesorar y cooperar con la formación académica del estudiante, a través de la búsqueda de alternativas de apoyo y consejería que faciliten su rendimiento educativo" (p.1). Este conjunto de actividades posicionan al orientador en su rol de tutor, como el responsable de consolidar las siguientes acciones: construir espacios dotados de oportunidades en las que el estudiante defina sus preferencias, identifique sus facultades y ejercite habilidades importantes, que le permitan enfrentar con efectividad y compromiso las demandas de su contexto.

Por su parte, Galagovsky (1993) define al orientador como un agente de cambio cuya experticia le permite guiar al estudiante a la comprensión de sus propios procesos de aprendizaje, así como a la aplicación de los mecanismos necesarios para procesar la información a través de "la reflexión sobre su funcionamiento cognitivo interno, la forma en que aprendió determinados contenidos; descubrir qué nuevas conexiones se hicieron en su estructura cognitiva, qué conceptos inclusores sirvieron de anclaje para los nuevos conceptos, qué estrategias se usaron" (p.36). Esta forma de caracterizar la metacognición puede entenderse como un proceso en el que el sujeto se vuelve consciente de las operaciones cognitivas, que se activan y que regulan el aprendizaje de nuevos conocimientos.
Para Rogoff (1993), el docente como orientador debe ofrecer estrategias y técnicas para producir nuevo conocimiento, valiéndose del "procesamiento, categorización, elaboración de conexiones y asociaciones entre experiencias y contenidos conceptuales, a través de las cuales estructurar unidades de información desde las que sea posible establecer relaciones significativas que faciliten el aprendizaje efectivo" (p.7). Esta perspectiva refiere al desarrollo de habilidades cognitivas que le permitan al orientado organizar lógicamente el mundo, reconstruir sus vivencias, así como garantizar el rendimiento académico para abordar con éxito las exigencias propias del sistema educativo.

Lo anterior indica que la orientación educativa propone acciones de intervención psicopedagógicas fundadas en la realización de ajustes técnicos, conceptuales y procedimentales que propicien la adecuación efectiva de los contenidos diseñados para cada nivel, como la manera idónea para abordar obstáculos desde múltiples enfoques. Ello en palabras de Torres (1999), no es más que "mirar las situaciones desde nuevos ángulos, superando las maneras tradicionales de atender las necesidades y cooperando con la imaginación de nuevos escenarios sobre los cuales actuar preventivamente" (p.5). Por ende, como agente estratégico, el orientador debe preguntarse lo siguiente: ¿qué? ¿dónde será el lugar a intervenir? ¿para qué se aplicarán las actividades planificadas? ¿cómo se conseguirán las metas propuestas? ¿quiénes serán los actores involucrados? ¿cuándo se desarrollarán las acciones de intervención? 
Por su parte, González (2012) define que orientar implícitamente refiere al "asesoramiento especializado en materia pedagógica y educativa como dimensiones que en las que se requiere de la promoción y el desarrollo de habilidades, competencias y destrezas para forjar actitudes positivas, de prevención y de mejora" (p.14). La posición anterior es igualmente compartida por Hernando, Juidías y Soto (2005), para quienes el orientador tiene atribuciones importantes enmarcadas en "la promoción del entusiasmo, la comunicación y la participación entre los estudiantes; y partiendo de estos procesos le es posible sus preferencias, definir sus objetivos y trabajar por consolidar su proyecto de vida" (p.7).

Por su parte, Rogers (1989) manifiesta que el orientador debe acercar al estudiante al entendimiento de su propósito en la vida, aspecto que cooperará con "el alivio de las tensiones cotidianas derivadas de la dinámica social, lo que derivará en la formación de personas maduras, comprensivas y capaces de enfrentar con éxito el surgimiento de eventuales tensiones futuras" (p.5). Esta apreciación permite afirmar que, el orientador por su nivel de especialización cuenta con la experticia para prevenir situaciones adversas, que pudieran generar escenarios negativos que al ser identificados y abordados a tiempo disminuirían sus efectos.

Ante este abanico de posibilidades en lo que a relaciones de ayuda se refiere, orientar -siguiendo a Rogers (1989)- implica llevar al sujeto a efectuar revisiones internas de las que se derive la exploración y el conocimiento de sus potencialidades. Pero, además, que "comprenda que dentro de sí existen recursos no explorados, que al ser utilizados conscientemente le permiten definir el perfil especifi$\mathrm{co}$, atendiendo a sus intereses ocupaciones, laborales, profesionales y personales" (p.4). Ello define otra dimensión de trabajo propio del orientador, que consiste en acompañar al sujeto en el proceso de escoger alternativas vocacionales, con la finalidad de facilitar la selección de oportunidades de estudio reales, y la continuidad en la formación universitaria de su preferencia. Todo esto implica que el usuario tome en cuenta las condiciones y demandas definidas por el contexto, así como por la dinámica que caracteriza al mercado laboral. Esta dimensión indica que el orientador debe contribuir con la realización de actividades informativas en las que se brinden aportes específicos, pertinentes y actualizados que satisfagan las necesidades y los intereses vocacionales del individuo.

Este cúmulo de exigencias ubican a la orientación como una actividad estratégica, que abarca áreas que por su complejidad, demandan el manejo detallado de las características sociales y culturales de los grupos con los que trabaja. De esto dependerá la integración de actores sociales tales como la familia, la comunidad y las instituciones como elementos necesarios para configurar procesos de elección vocacional y profesional competentes, que respondan y se adecuen a los objetivos de desarrollo personal y social. 
De esta manera es posible afirmar que, el orientador tiene atribuciones como la creación de perfiles profesionales que atiendan a los intereses personales, en los que se tomen en cuenta las actitudes y preferencias del estudiante; aportándole una visión global que deje entrever las ventajas, beneficios y posibles riesgos que entrañan el optar por alternativas que no respondan a necesidades reales, sino a imposiciones derivadas de los agentes socializadores. Por tal motivo, orientar vocacionalmente incluye la realización de simulacros, socio-dramas y actividades educativas, mediante las cuales el estudiante se involucre en la asunción de roles profesionales, que reflejen las responsabilidades que a futuro deberá asumir.

Orientar es, entonces, un proceso y una exigencia enfocada en preparar al individuo para enfrentar los obstáculos que frecuentemente emergen del entorno, y que determinan de manera significativa la conformación de un agente con las actitudes, las capacidades y la inteligencia para reaccionar, positivamente, ante los riesgos a los que se asumen como situaciones recurrentes con repercusiones sobre su identidad, su realización personal y reconocimiento social. En palabras de Corkille (1970), la orientación persigue que de manera natural el estudiante descubra "sus verdaderas habilidades, aptitudes y potencialidades, lo que hará más probable el consolidar el éxito y, también, se considere a sí mismo adecuado para asumir responsabilidades y sortear los retos" (p.26).
Lo dicho hasta ahora refiere a la formación para la vida (Torres, 1999) y para participar autónomamente de las actividades que se realizan en su espacio de acción, entendiendo que este se encuentra movido por la incertidumbre; el riesgo y los cambios recurrentes como características. Estas, para ser atendidas oportunamente, requieren de la construcción de lazos de cooperación y de relaciones personales sólidas, así como la consolidación de una autoimagen positiva (Corkille, 1970; Morales, 2018b). Estas sirven de vehículo para actuar con confianza, libertad y con las actitudes necesarias para evaluar alternativas $\mathrm{y}$ tomar decisiones en forma acertada.

Se infiere entonces, que la labor educativa del docente como orientador, se enfoca en preparar a los integrantes del sistema educativo para sobrellevar los dilemas, manejar los conflictos y comprender con madurez que existente una co-responsabilidad que nos impulsa a participar de la vida social, a través de la construcción de soluciones que coadyuven con el crecimiento propio y del otro. Esta postura humanista hace referencia a la necesidad de integrar a la orientación como proceso implicado en la promoción de ideales y valores sociales, que preparen al individuo para responder oportunamente a los requerimientos de transformación y resolución de situaciones que emergen de su medio. Tal responsabilidad posiciona a la orientación educativa como la encargada de promover la formación personal efectiva, en la que el orientado deje a un lado el individualismo que imposibilita la generación de mejores condiciones de vida 
para el colectivo; $y$, en su lugar, logre jerarquizar las necesidades. Es decir, darle prioridad a aspectos tales como la solidaridad, la cooperación y empatía; valores que por su relevancia en el presente siglo, posibilitan la participación efectiva dentro de los procesos de intervención y de accionar colectivo, que procuran la atención y el desarrollo integral del escenario social.

Este nivel de integración a la dinámica social debe ser visto como un eje educativo, al que se le atribuye la incorporación progresiva y sistemática del sujeto a las líneas de acción; dimensiones y escenarios en los que se requiere su actuación competente, comenzando por el espacio comunitario del que hace parte y con el que deberá sentir empatía, confianza y mayor nivel de compenetración. Estas condiciones vienen a posibilitarle el acceso a los problemas, a la construcción de soluciones $y$, a la unificación y la integración de esfuerzos de los que han sido vulnerados, excluyéndolos de los beneficios propios de la calidad de vida.

Al respecto, la psicología social le atribuye al orientador funciones importantes, entre las que destacan, según Barra (1998), la "búsqueda de ideales comunes que identifique al sujeto con sus pares y sus necesidades; estableciendo con ello nexos emocionales y afectivos entre los miembros del grupo como medios para conseguir condiciones de estabilidad donde el bien común factor fundamental" (p.25). Este rol protagónico no es más que el ejercicio de la influencia colectiva y la capaci- dad de cohesión fundada sobre la reciprocidad, como valores sociales que dan lugar a la convicción necesaria para actuar desde posiciones de liderazgo efectivo y transformador.

En este sentido, y siguiendo a Barra (1998), la orientación enfatiza en la preparación del individuo para "entender los procesos de socialización institucional, participar en la cohesión grupal, asumir roles en atención a las convencionales sociales y desarrollar habilidades comunicativas, relaciones humanas $y$ toma de decisiones como respuestas efectivas que coadyuven con la resolución de conflictos" (p.15). Estas exigencias, desde la psicología educacional, son definidas como la creación de espacios para el aprendizaje, en los que el orientado logre edificar un clima favorable en el aula y demás espacios socio-educativos.

Lo planteado según Rogers (1996), exige que el escenario educativo fomente actitudes activas y flexibles, capaces de "enfrentar los cambiantes, mudables y fluidos problemas actuales" (p.7). Ante esta caracterización, el orientador aprovechando su facultad para actuar en los escenarios educativos, sociales y comunitarios, debe ser capaz de generar procesos en los que el estudiante y demás actores educativos, experimenten situaciones significativas que los sensibilicen y guíen a forjar nexos interpersonales positivos, adecuados a las demandas propias de la realidad a la que pertenecen. Esto, en términos de Gardner (1996), hace referencia a la necesidad de promocionar el ejercicio de "habilidades para enfrentar desafíos y situaciones abrumado- 
ras, que al ser superadas generan sensación de satisfacción, así como de realización personal" (p.4).

$\mathrm{Al}$ respecto, perspectivas constructivistas han planteado la necesidad de acompañar al estudiante en los procesos de cambio, debido a que estos por condición natural generan sensaciones, experiencias y frustraciones con impactos negativos que pudieran imposibilitar el hacer frente a los retos que, por su complejidad, demandan persistencia y esfuerzo. Siguiendo a Rogers (1996), orientar implica "adoptar una actitud de cooperación con el otro, a quien "se le guía en procesos complejos, superando los miedos y vacilaciones que el estudiante experimenta cuando se enfrenta a problemas nuevos, en un intento por conseguir el logro de sus objetivos personales" (p.9).

En virtud de lo anterior, la orientación educativa debe entenderse como el proceso de conducción que acompaña al individuo en la transición de explorar su interior, en una búsqueda persistente de potencialidades reales que propicien -según expone Maslow (1954)- la "satisfacción de necesidades y sentimientos de autoestima, valía, fuerza, capacidad y adecuación. Estas por su importancia, le hacen útil y apto para responder con elevado nivel de competitividad, las diversas situaciones que emergen de su relación con el mundo" (p. 80).

En esta misma línea de pensamiento, Novak y Gowin (1998), haciendo referencia al rol que tiene el orientado, proponen que este debe asumir la responsabilidad de hacer cumplir sus intereses y preferencias, así como poner al servicio de terceros el desempeño de actividades útiles, que deriven en funciones sociales pertinentes. Para esto se requiere de "una actitud dada a la negociación, a compartir, discutir y convenir expresiones democráticas que posibilitan participar, efectivamente, dentro de los asuntos colectivos de amplio impacto transformador" (p.9).

Lo expuesto apunta hacia la formación de un ciudadano con habilidades sociales, de liderazgo y compromiso, que coadyuven en la construcción de bienestar generalizado en su entorno, a través del entendimiento de las necesidades de terceros y de la oferta de soluciones efectivas. Con relación a este aspecto, Camps (2000) manifiesta que, se trata de involucrar y sensibilizar al orientado para que asuma "que sus necesidades son semejantes si no iguales a las del resto, por lo que es inminente la unificación de esfuerzos para garantizar que todos puedan vivir en igualdad de condiciones" (p.2).

Todo esto dentro del marco constructivista significa preparar al individuo para que actúe como agente transformador, capaz de hacer uso de los recursos que el entorno le provee, y unificar sinérgicamente los esfuerzos de terceros en un intento por abordar con inteligencia el proceso de desarrollo propio y de sus pares. A estos últimos se les debe considerar actores fundamentales para articular acciones que procuren satisfacer necesidades comunes, en un clima de solidaridad en el que se gestionen colectivamente la solución a los problemas sociales. 
Lograr tales comportamientos y actitudes, demanda que el docente como orientador propicie la interacción con situaciones reales, propias del contexto, y potencialmente transformables, con el objeto de promover el sentido de pertenencia y responsabilidad, que inviten al orientado a reflexionar sobre cómo incidir con eficacia en situaciones que, por su importancia, hacen funcional las relaciones grupales. Ello propicia las condiciones para la actuación social pertinente que, vinculada con el liderazgo, promuevan el crecimiento propio y el de los que integran su realidad inmediata.

Por tal motivo, la orientación entraña la promoción de procesos interacción con experiencias estratégicas. El protagonismo del sujeto, en la dirección de acciones relevantes que definan el cumplimiento de determinados intereses comunes, así como la jerarquización, ajuste y priorización de metas, con la intención de favorecer la construcción de formas de convivencia saludables y ricas. Esto representa oportunidades de crecimiento para todas las dimensiones del ser humano, en las que se posibilite el despliegue, desenvolvimiento y configuración de condiciones óptimas y saludables de vida. Al respecto, la teoría crítica de la educación propone como factor indispensable la formación de actitudes individuales, que unidas al sentir colectivo, favorezcan la conformación de una sociedad con mayores niveles de equidad, igualdad y participación como valores medulares, para atravesar con eficacia los obstáculos y las crisis que se puedan presentar.
En palabras de Freire (2002), lo anterior responde en esencia a los cometidos que debe perseguir la educación en el presente siglo, los cuales deben girar en torno a la búsqueda recurrente de "valores humanos irrenunciables como la solidaridad, la justicia, el respeto entre congéneres, con el propósito de erradicar la destrucción signada por la agresión indiscriminada y por las relaciones de dependencia que solo traen problemas y conflictos entre los seres humanos" (p.1).

Para conseguir tales objetivos, Bisquerra y Pérez (2007) proponen la creación de condiciones oportunas para que el individuo aflore las habilidades sociales que lo movilicen a trabajar para crear condiciones óptimas de vida, en las que se reconozca e integre al otro, valiéndose de la aceptación como una actitud positiva que "involucre a sus pares en su propio proceso de desarrollo y, a la vez, les aporte experiencias que los preparen para realizarse a nivel personal, interpersonal y relacional" (p.3).

Esta postura redefine a la orientación educativa, como el proceso socioeducativo que procura el crecimiento humano, la promoción de actitudes altruistas, de ayuda y cooperación, que activen su sensibilidad para atender las necesidades sociales, con un elevado nivel de responsabilidad y autonomía; pero, además, con la disposición para gestionar soluciones auténticas apegadas al bien común. Lo dicho desde la pedagogía de las emociones se interpreta como la adquisición de competencias relacionadas con el bienestar no solo personal, sino colectivo (Bisquerra, 2009), que im- 
pulse al sujeto a procurar la realización de sus propios objetivos, así como los de otros actores sociales.

Por consiguiente, orientar consiste en adentrar al sujeto en una dinámica motivacional que le lleve definir de manera activa su proyecto de vida, mediante el accionar personal, producto de una actitud equilibrada que le acompañe a identificar sus potencialidades y a alcanzar sus propósitos con suficiente estabilidad emocional; y con la intensidad para satisfacer necesidades tales como el reconocimiento del otro, el autoconcepto y la autoestima. Por su parte, la teoría de las necesidades propone que la orientación refiere a la creación de las condiciones para que el orientado logre, según Maslow (1954), “la consolidación de sentimientos de autoconfianza, de estatus, la superación de sensaciones de inferioridad, debilidad e impotencia" (p.80).

En palabras de Corkille (1970), es un profesional orientador capaz de despertar en el sujeto el interés por explorar en su interior, con el propósito de "descubrir sus potencialidades como herramientas necesarias para alcanzar niveles óptimos de salud mental, condición fundamental para construir relaciones positivas en cualquier clima psicológico en el que le toque vivir" (p.15). Orientar - por consiguiente- se asume como el medio para formar individuos con las competencias socioemocionales necesarias para manejarse en escenarios conflictivos y complejos; características que exigen la disposición de su creatividad, inteligencia e innovación como aspectos necesarios para su la realización social y cultural.
Desde una posición crítica, Illich (1985) manifiesta que la educación actual debe guiar a sus participantes a "organizar sus propias vidas entorno a sus propias experiencias y recursos, dentro de su propia realidad, con el objeto de desarrollar condiciones de bienestar personal $y$ social que minimicen los niveles de frustración y destructividad" (p.5). Esto implica que, orientar significa crear espacios en los que se oferte atención especializada; que de manera progresiva y sistemáticamente, se guie al sujeto en la superación de conflictos internos, así como en el rompimiento de relaciones de dependencia psicológica que imposibilitan al orientado valerse por sí mismo.

Por ende, orientar como función inherente a la educación debe entenderse desde una perspectiva amplia como el proceso de integrar al sujeto en escenarios complejos, a través de acciones de interacción progresiva con los actores de los que depende en mayor medida su desarrollo social como partícipe del espacio comunitario. Siguiendo a Illich (1985), orientar consiste en atender "la dimensión psicológica, laboral, el tiempo libre, la vida ciudadana e incluso familiar como espacios de los que depende, en menor o mayor medida, la formación de hábitos y de experiencias positivas que determinarán el funcionamiento efectivo del hombre" (p.8). Esto permite inferir que, la orientación como proceso de atención integral, involucra cometidos como: mayores niveles seguridad, atribución de significado a las experiencias y la sensación de percibirse dotado de virtudes y exitoso. 
La psicología cognitiva ha propuesto que el docente en su función de guía y orientador debe establecer puentes entre la vida social y los procesos formativos, procurando y promoviendo el examen de las necesidades colectivas y las exigencias emergentes del espacio social. Estas deben ser consideradas para redefinir, transformar y adecuar los propósitos educativos en un intento por formar individuos con el potencial innovador para aportar soluciones pertinentes y con implicaciones en todos los campos de la sociedad (Piaget, 2001).

Por su parte, las teorías constructivistas defienden la idea de asumir a la orientación como el proceso encargado de acercar, progresivamente, al individuo a los factores de socialización, que lo preparen para la convivencia solidaria y la búsqueda del bien común; condiciones que por su relevancia requieren, según expone Colls y otros (1998), del "desarrollo globalmente entendido. Esto supone incluir también las capacidades de equilibrio personal, de inserción social, el fortalecimiento de las relaciones interpersonales y de la empatía necesaria para cooperar en la construcción de espacios sanos" (p.15).

En apoyo a esta posición, Bisquerra y Pérez (2007) proponen que la orientación debe entenderse como una actividad que involucra la promoción y el despliegue de competencias para "mantener buenas relaciones sociales con otras personas, lo que implica dominar las habilidades sociales; la capacidad para comunicarse de forma efectiva, manejar el respeto, las actitudes pro-sociales y el asertividad como herramientas para participar activamente $y$ transformar su propia realidad" (p.11).

En este sentido, se infiere que sobre el orientador recaen responsabilidades y funciones enfocadas en la promoción de conductas y comportamientos saludables, así como habilidades sociales para establecer relaciones interpersonales en escenarios familiares, educativos y comunitarios. Orientar es, pues, cooperar en formación de actitudes proactivas, desde las cuales enfrentar los problemas de manera inteligente y haciendo uso de la creatividad como instrumento de transformación, que procura la búsqueda de niveles elevados de excelencia.

A partir de lo dicho, se deduce que la orientación y su relevancia se justifican por constituir un instrumento socioeducativo y psicopedagógico, con el potencial para diseñar acciones de transformación individual y colectiva, al ser capaz de pronosticar posibles alternativas y vías idóneas, a través de las cuales intervenir y prevenir situaciones conflictivas que pudieran alterar la convivencia social y educativa (Galeano, 1998). Esta afirmación define a la orientación educativa como una actividad que facilita la elaboración de proyecciones, que permitan minimizar el efecto de los problemas, así como diseñar programas de amplio alcance a todas las dimensiones y espacios en los que se desenvuelve el hombre.

Lo dicho refiere implícitamente a los cometidos de la educación actual, en los que se aprecia la formación activa y la integración del ciu- 
dadano a las actividades propias de su espacio de convivencia; condiciones que apuntan a la práctica de valores como: el compromiso y la autonomía necesaria para tomar decisiones, y resolver de manera competitiva y creativa los conflictos que emergentes. En este sentido, la orientación educativa -como proceso de cooperación al desarrollo humano- debe trabajar ser capaz de integrar a los actores de la comunidad educativa en la construcción de procesos interactivos en los que participen, $y$ asuman roles protagónicos que conduzcan al desarrollo humano (Bronfenbrenner, 1987).

Para Maturana (1990), orientar en momentos tan cruciales exige atender tanto propósitos sociales como individuales, en los que el sujeto se sensibilice e involucre en la resolución de conflictos de su contexto. Esto significa prepararlo para que interactúe y participe como generador de nexos sólidos de convivencia, que amplíen las brechas de bienestar social. Davini (2015) expone que, formar en tiempo de cambios demanda "el desarrollo de capacidades para la acción en la práctica; lo que implica familiarizar al sujeto con situaciones reales y significativas en las que vivencie en parte las exigencias de su contexto" (p.13).

Camps (2000) deja ver que, la orientación como proceso educativo debe ser capaz de "generar bienestar como condición fundamental para que el individuo pueda actuar moralmente, y con compromiso social, para resolver los continuos conflictos y problemas que emergen de las relaciones sociales" (p.1). Por tal motivo, en el contexto educativo y co- munitario no es más que, la consolidación de mayores niveles de convivencia digna, mediante la búsqueda recurrente de oportunidades de crecimiento integral, como acciones pensadas desde lo colectivo, y no desde el individualismo, al que le atribuye en la modernidad la emergencia de desigualdad social.

A partir de lo planteado, se comprende la orientación como un eje medular para todo proceso socioeducativo, pues sus cometidos se enfocan en la consolidación de un proyecto inclusivo, en el que entiende que convivir con el diferente, le permite enriquecer su humanidad y mitigar los efectos de la discriminación y la intolerancia. Al respecto Camps (2000) coincide con Lepovetsky (2000) al decir que, orientar constituye una responsabilidad socioeducativa que precisa la formación del estudiante para desenvolverse en sociedad; para transformarla y mejorarla, a través de la inclusión del otro, del marginado por las circunstancias socio-históricas.

Orientar es, entonces, fomentar la cultura de la corresponsabilidad en la que se deje a un lado la individuación, y se despierte la convicción del pluralismo cultural; la inclusión y la tolerancia como valores que -en el presente siglo- toman especial importancia por sus aportaciones a la convivencia humana, ideal que procura la eliminación de las diferencias y la unificación de la diversidad. Esto para la psicología humanista constituye un medio poderoso para crear un mundo en el que los ciudadanos en general sean empáticos, altruistas y constructores de espacios para el 
desarrollo del potencial humano (Maslow, 1954; Rogers, 1989).

Para el psicoanálisis, la formación del ser humano debe enfocarse en la transformación recurrente de su naturaleza, con el propósito de hacer que afloren sus cualidades, su disposición a la adaptación social y la búsqueda de mayores niveles de independencia, que le permitan actuar de manera autónoma. Orientar, desde esta perspectiva, significa conducir a la exploración de sus facultades, de las cualidades y potencialidades humanas que le aporten sentido a su existencia; aspectos cuyo enfoque no es otro que la educación de un individuo equilibrado y capaz de integrarse socialmente. Fromm (1964), al respecto, propone que el ideal del desarrollo humano persigue "que la persona logre alcanzar la libertad, la espontaneidad y la expresión auténtica de sí misma; esto supone, el alcance de sus metas" (p.20).

En suma, el rol orientador del docente en el contexto educativo y comunitario involucra la creación de condiciones, en las que el individuo logre emprender su participación en el proceso de asumir con responsabilidad y autonomía; el desarrollo no solo de su dimensión personal, sino de su función como agente capaz de generar bienestar social, a través de actitudes comprometidas en las que coopere con la satisfacción de las necesidades de quienes son parte del contexto de vida inmediato. Estos cometidos indican que, la orientación hace posible la generación de mejores condiciones de bienestar, pues como proceso inherente a la educación, contribuye con la formulación de recomendaciones y posibles alternativas, mediante las cuales logra integrarse competitivamente al mundo social.

\section{Conclusiones}

Como se logró apreciar, los procesos complejos por los que atraviesa el ser humano, los conflictos en las diversas etapas evolutivas y las dificultades que emergen de las relaciones que se dan en su entorno, han propiciado quiebres en la personalidad $y$, en ocasiones, la disociación interna del individuo; lo que ha sobrevenido, según Elizalde (2012), en "infelicidad, dolor, angustia, insatisfacción y sufrimiento" (p.79). Frente a esta realidad, orientar ha tomado especial importancia por considerarse no solo un proceso de ayuda, acompañamiento y asesoría, sino en el proceso de atención integral capaz de motivar la transformación del ser, el descubrimiento de las potencialidades individuales y la definición creativa de alternativas para convivir, y alcanzar niveles dignos de calidad de vida.

De este modo, la orientación debe asumirse como el proceso socioeducativo cuyo enfoque en la actualidad es la formación de competencias sociales, preferencias vocacionales y la consolidación de aptitudes como factores inherentes al desarrollo humano en sus diversas dimensiones. Esto significa integrar al sujeto que educa en el compromiso y la responsabilidad social, a las que se entienden desde los principios de la educación para la ciudadanía como condiciones necesarias para resolver los problemas derivados de la desigualdad. En este sentido, orientar no es más que 
la relación de ayuda y acompañamiento profesional que se le ofrece al contexto educativo y comunitario, con el propósito de que sus actores sean capaces cumplir con los siguientes cometidos: participar competitivamente en la construcción de escenarios pacíficos donde sea posible la convivencia, la comunicación y el reconocimiento de la diversidad (cultural, ideológica, entre otras).

Por tal motivo, la orientación se posiciona como un proceso que, más allá de atender las necesidades del escenario educativo, procura la educación emocional que le permita al sujeto procesar, adecuarse y aceptar los cambios. En otras palabras, orientar en tiempos complejos y conflictivos constituye el medio para motivar la autoconciencia, la empatía, la autoestima y la disciplina necesaria para afrontar retos personales y colectivos; que para ser resueltos requieren de una personalidad autónoma, de liderazgo y de la capacidad para trabajar en equipo, reconociendo que en la diversidad de esfuerzos, así como en la unificación de intereses, es posible la resolución de los desafíos que se imponen a diario.

También, puede entenderse a la orientación como una función inherente a la docencia que persigue promover la revisión y valoración interna de las cualidades propias, el descubrimiento y la exploración de alternativas que pudieran guiarle a una acertada toma de decisiones en lo que respecta a: resolución de conflictos, escogencia de opciones vocacionales y definición de preferencias profesionales, que les permitan alcanzar la autorrealización de sus propios proyectos de vida. Se trata de propiciar las condiciones necesarias para tomar decisiones pertinentes a partir del uso del pensamiento crítico, y de la confrontación de los retos con actitud positiva (Sarramona, 2002).

En síntesis, orientar en un momento convulsionado como el que vivimos, se suma a los procesos de educación y formación para la vida, que persigue entre otros propósitos, ofrecer asesoramiento y guiatura para que el sujeto logre alcanzar estabilidad emocional y socio-afectiva, así como el desarrollo humano integral que posibilite su desempeño competitivo frente a las exigencias que le impone una realidad en cambio constante.

En tal sentido, la orientación como proceso de ayuda busca que el individuo alcance su mayor potencial y logre convertirse en el conductor autónomo capaz de: generar desarrollo personal, gestionar sus necesidades y cooperar con la existencia digna del otro; a quien se asume como indispensable para la construcción de escenarios en los que primen los principios de la calidad humana, el diálogo y la fraternidad. 


\section{Referencias}

Bisquerra, R. (2009). Psicopedagogía de las emociones. Madrid: Editorial Síntesis.

Bisquerra, R., y Pérez, N. (2007). Las competencias emocionales. Revista Educación XXI,10, 6182. Recuperado de http://revistas.uned.es/index.php/educacionXX1/article/view/297/253

Bronfenbrenner, U. (1987). La ecología del desarrollo humano. Barcelona: Paidós.

Camps, V. (2000). Los valores de la educación. Madrid: Editorial Anaya.

Cañas, C. A.; Campoy, A. T. J. y Pantoja V. A. (2005). La función tutorial: valoración y necesidades del profesorado. Bordón: Revista de orientación pedagógica. 57 (3), 297-314. Recuperado de https://www4.ujaen.es/ apantoja/mis_articulos/fun_tuto_bordon_57_3.pdf

Coll, C. y et al. (1998). El constructivismo en el aula. Barcelona: Editorial Graó.

Corkille, D. (1970). El niño feliz su clave psicológica. Barcelona: Granica Editor.

Daros, W. (2009). El entorno social y la escuela. Rosario: Editorial Artemisa.

Davini, M. (2015). La formación en la práctica docente. Buenos Aires: Editorial Paidós.

Elizalde, A. (2012). Desarrollo humano y ética para la sustentabilidad. México: PNUMA.

Freire, P. (2002). Educación y cambio. Recuperado de http://derechoepja.org/wp-content/ uploads/2015/05/freire-paulo_educacicion-y-cambio.pdf

Fromm, E. (1964). El psicoanálisis en la sociedad contemporánea. México: Fondo de Cultura Económica.

Galagovsky, L. (1993). Hacia un nuevo rol docente. Buenos Aires: Editorial Troqvel.

Galeano, E. (1988). La escuela del mundo al revés. Madrid: Siglo XXI.

García, L. y González, N. (2010). Competencias básicas. Tutor en educación superior: el desafío de un a construir. Congreso Iberoamericano de Educación Metas del siglo XXI, 1-7. Buenos Aires: Universidad de Buenos Aires.

Gardner, H. (1996). La mente no escolarizada. Cómo piensan los niños y cómo deberían enseñar las escuelas. Buenos Aires: Editorial Paidós.

Goleman, D. (1998). Inteligencia emocional. Barcelona: Editorial Kairós. S.A.

González, M. (2012). El rol del orientador en el siglo XXI. ACLPP Informa, (27), 2-15. 
Hernando-Gómez, A.; Juidías-Barroso, J. y Soto-Rosales, A. (2005). Estudio de los roles y funciones del orientador de educación secundaria a través de la técnica del grupo de discusión. International Journal of Developmental and Educational Psychology, 2 (1), 673-683.

Illich, I. (1985). La sociedad desescolarizada. Ciudad de México: Editorial Joaquín Moritz.

Lipovetsky, G. (2000). La era del vacío. España: Editorial Anagrama.

Maslow, A. (1954). Motivación y personalidad. Nueva York: Harper and Row.

Maturana, H. (1990). Emociones y lenguaje en educación política. Colección HACHETTE/COMUNICACIÓN CED.

Montero, M. (2004). Introducción a la psicología comunitaria. Desarrollo, conceptos y procesos. Buenos Aires: Editorial Paidós.

Morales, J. (2018a). La violencia en escenarios educativos: un acercamiento multidisciplinario para su comprensión. Innovaciones Educativas, 2 (29), 81-94.

Morales, J. (2018b). Una aproximación a la tipificación de la violencia. Revista Ciencias Sociales y Educativas, 8 (1), 89-104.

Novak, J. y Gowin, D. (1998). Aprendiendo a aprender. Barcelona: Ediciones Martínez Roca.

Piaget, J. (2001). Psicología y pedagogía. Madrid: Editorial Booket.

Ponce, S.; García, B.; Islas, D. y Serna, A. (2018). De la tutoría a la mentoría. Reflexiones en torno a la diversidad del trabajo docente. Revista Páginas de Educación, 11(2), 215-235.

Rogers, C. (1989). El proceso de convertirse en persona. Barcelona: Editorial Paidós.

Rogers, C. (1996). Libertad y creatividad en la educación. Barcelona: Editorial Paidós.

Rogoff, B. (1993). El desarrollo cognitivo en el contexto social. Barcelona: Paidós.

Sarramona, J. (2002). Desafíos de la escuela en el siglo XXI. Barcelona: Editorial Octaedro.

Sen, A. (2000). Desarrollo y libertad. Barcelona: Editorial Planetas.

Torres, R. (1999). Nuevo rol docente: ¿qué modelo de formación, para qué modelo educativo. Madrid: Fundación Santillana.

UNESCO (2015). Orientación y Desarrollo de Capacidades sobre Educación para la Ciudadanía Mundial en América Latina y el Caribe. Reporte Informativo. Santiago de Chile. 